\title{
破裂脳動脈瘤に続発する水頭症の検討
}

\author{
宮田 伊知郎, 石 光宏, 西 浦司 \\ 正 岡 哲也, 松海 信彦
}

\section{Hydrocephalus Following Subarachnoid Hemorrhage from Ruptured Intracranial Aneurysms}

Ichiro Miyata, M.D., Hiroshi Ishimitsu, M.D., Tsukasa Nishiura, M.D., Tetsuya Masaoka, M.D., and Nobuhiko Matsumi, M.D.

Department of Neurosurgery, Iwakuni National Hospital, Iwakuni, Japan

\begin{abstract}
Summary : Communicating hydrocephalus is one of the secondary complications of the subarachnoid hemorrhage from ruptured intracranial aneurysms. Possible factors for hydrocephalus were analyzed retrospectively in 183 patients with surgically treated ruptured intracranial aneurysms. The site of aneurysms were anterior communicating artery (54 cases), posterior communicating artery (66 cases) and middle cerebral artery (63 cases). Of the 170 cases, except 13 cases who died in the acute stage, shunts were required in 66 cases $(39 \%)$ because of hydrocephalus. The incidence of hydrocephalus was significantly higher in those patients who had one or more of the following factors: (1) advanced age, (2) the aneurysm was located near the midline, (3) higher preoperative clinical grades, (4) thick clots on CT, (5) delayed ischemic neurological deficits and (6) a decompressive craniectomy. Surgical results of patients with hydrocephalus were worse than those of patients without hydrocephalus.
\end{abstract}
Key words :
- hydrocephalus
- subarachnoid hemor- rhage
- ruptured aneurysm
- shunt

\section{はじめに}

破裂脳動脈瘤に続発する水頭症は, 急性期においては脳 循環などに強い影響を及ぼし，また慢性期にはいわゆる正 常圧水頭症として特有な臨床症状を引き起こし, 予後を左 右する上で重要な病態である. 今回自験例における水頭症 の発現因子について検討したので報告する.

\section{対象と方法}

1984 年 1 月から 1991 年 12 月までの 8 年間に直達手術 を行った破裂脳動脈瘤症例のうち, 内頸動脈系の代表的動
脈瘤である前交通動脈瘤 (AcomA) 54 例, 後交通動脈瘤 (IC-PC) 66 例, 中大脳動脈瘤 (MCA) 63 例, 計 183 例を 対象とした (Table 1). 我々の治療方針は, 原則として発 症 3 日以内の急性期手術である. 術前までの抗線溶剂の使 用は, 1 日 $2 \mathrm{~g}$ 以下 3 日以内を原則とした. 術中クモ膜下 血腫は, 積極的には除去していない. 脳槽ドレナージは全 例に行い，基本的には 2 週間留置したが，ウロキナーゼな どを使用しての脳槽灌流は行っていない. 外減圧術は急性 期手術例全例に行った時期もあるが, 基本的には Hunt \& Kosnik $^{8)}$ grade III 以上で CT group ${ }^{3)}$ III, IVの症例に行った. 急性期手術の行われなかった症例は, 発症 4 日以降に入院

国立岩国病院 脳神経外科(受稿日 1993.2.12)〔連絡先：干740 岩国市黒磯町 2-5-1 国立岩国病院 脳神経外科 宮田伊知郎〕 〔Mailing address: Ichiro Miyata, M.D., Department of Neurosurgery, Iwakuni National Hospital, 2-5-1 Kroiso-cho, Iwakuni 740, Japan] 
した例や grade の壾い例などであった.

急性期死亡 13 例を除いた 170 例のうち，水頭症が発現

し髄液シャント手術を施行した症例は66例であり，水頭症 発現率 (H率) は39\%であった。これら 66 例についてシャ

ント手術の有効性を検討した。

水頭症は大きく 2 群に分けられた，すなわち痴呆，尿失 禁，歩行障害などの臨床症状があり，CT 上 PVL を伴っ た脳室拡大 (明確な測定基準は設けていない)を認めるもの を正常圧水頭症 (NPH)：group A と診断した。症例によ っては, RI cisternography を行い髄液循環障害のあるこ とを確認したが，診断には臨床症状を優先させた。一方， 急性期に行ったドレナージを閉塞あるいは抜去すると脳室 の進行性拡大とともに意識レベルの低下をきたす例，クモ 膜下出血や脳血管攣縮による意識障害があり, しかも CT 上進行性に脳室拡大, PVLの出現を認めた例は, 髄液循 環障害による脳室拡大と考え水頭症： group B と診断した. 水頭症：group A と考えられた症例は 20 例で，クモ膜下 出血発症からシャント手術までの期間は平均 56 日であっ た。このうち手術により症状の改善がみられたのは 13 例 $65 \%$, 部分改善 5 例 $25 \%$, 不変および悪化各 1 例, 改善 および部分改善を合わせた症状改善率は $90 \%$ であった。 水頭症：group B と考えられた症例は 46 例で, 発症から シャント手術までの期間は 47 日であった. シャント術後 1 力月以内に意識清明になったものを改善, 見当意識障害 や痴呆などが残ったものを部分改善としたところ，改善 9 例 $20 \%$, 部分改善 18 例 $39 \%$, 不変 18 例 $39 \%$, 悪化 1 例 $2 \%$ で，症状改善率は $59 \%$ と低かった (Table 2).

2 群の水頭症はクモ膜下出血を発端に発生したものであ り，その発現因子は共通であると考え一括して検討した。 なお，デー夕の分析には比率の差の検定 ( $Z$ 検定)によって 行い，実際の計算には“医療向統計分析システム”（日本 能率協会総合研究所）を使用した.
Table 1 Clinical characteristics of ruptured aneurysms

\begin{tabular}{|c|c|c|c|}
\hline & AcomA (\%) & IC-PC (\%) & $\operatorname{MCA}(\%)$ \\
\hline No. & $54(30)$ & $66(36)$ & $63(34)$ \\
\hline Mean age & $58.0 \pm 13.1$ & $60.6 \pm 11.5$ & $59.9 \pm 12.3$ \\
\hline Sex male & $29(54)$ & $8(12)$ & $17(23)$ \\
\hline female & $25(46)$ & $58(88)$ & $46(73)$ \\
\hline \multicolumn{4}{|c|}{ Preope. grade (Hunt \& Kosnik ${ }^{8)}$ ) } \\
\hline Ia & 7 (13) & $12(18)$ & $5(8)$ \\
\hline I & $7(13)$ & $1(2)$ & $3(5)$ \\
\hline II & $17(32)$ & $27(40)$ & $24(38)$ \\
\hline III & $13(24)$ & $13(20)$ & $12(19)$ \\
\hline IV & $8(15)$ & $12(18)$ & $15(24)$ \\
\hline V & $2(3)$ & $1(2)$ & $4(6)$ \\
\hline \multicolumn{4}{|c|}{ CT group (Fisher et $a l^{3)}$ ) } \\
\hline I & $0(0)$ & $5(8)$ & $0(0)$ \\
\hline II & $22(41)$ & $25(38)$ & $16(26)$ \\
\hline III & $26(48)$ & $34(51)$ & $33(52)$ \\
\hline IV & $6(11)$ & $2(3)$ & $14(22)$ \\
\hline \multicolumn{4}{|c|}{ Time of surgery } \\
\hline day $0-3$ & $39(72)$ & $50(76)$ & $53(84)$ \\
\hline $4-14$ & 7 (13) & $3(4)$ & $5(8)$ \\
\hline $15^{-}$ & $8(15)$ & $13(20)$ & $5(8)$ \\
\hline
\end{tabular}

AcomA indicates anterior communicating artery; IC-PC, internal carotid-posterior communicating artery junction; MCA, middle cerebral artery; CT, computed tomography

\section{結果}

水頭症発現因子として年齢，動脈瘤の部位，術前重症度 (Hunt \& Kosnik)，CT 所見 (Fisher 分類)，脳血管攣縮に よる Delayed Ischemic Neurological Deficit (DIND)の有 無，外減圧の有無をあげ，それぞれの $\mathrm{H}$ 率につき検討し た。なお，DINDの診断基準は Kassell ら ${ }^{10)}$ の報告に準じ 臨床症状から判定した。

\section{1. 年 齢}

65 歳未満の症例では 100 例中 26 例 $26 \%$ に水頭症をきた したが，65 歳以上の高齢者では 70 例中 40 例 $57 \%$ で 65 歳 未満に比べて高率であった $(p<0.01)$.さらに年齢別に $\mathrm{H}$

Table 2 Surgical results related to hydrocephalus

\begin{tabular}{c|c|cccc}
\hline \multirow{2}{*}{ Symptoms } & \multirow{2}{*}{$\begin{array}{c}\text { No. } \\
\text { of } \\
\text { cases }\end{array}$} & \multicolumn{4}{|c}{ Surgical results (\%) } \\
\cline { 3 - 6 } & improve. & $\begin{array}{l}\text { partial } \\
\text { improve. }\end{array}$ & unchanged & $\begin{array}{c}\text { aggra- } \\
\text { vation }\end{array}$ \\
\hline $\begin{array}{c}\text { Trias } \\
\text { of } \\
\text { NPH }\end{array}$ & 20 & $13(65) \quad 5(25)$ & $1(5)$ & $1(5)$ \\
\hline $\begin{array}{c}\text { Disturbance } \\
\text { of }\end{array}$ & 46 & $920 \%$ & $18(39)$ & $18(39)$ & $1(2)$ \\
consciousness & & \multicolumn{2}{|c|}{$59 \%$} & & \\
\hline
\end{tabular}

NPH indicates normal pressure hydrocephalus; improve., improvement. 
Table 3 Incidence of hydrocephalus related to age

\begin{tabular}{c|r|rrr}
\hline \multirow{2}{*}{$\begin{array}{c}\text { Age } \\
\text { (yrs })\end{array}$} & \multirow{2}{*}{$\begin{array}{c}\text { No. of } \\
\text { cases }\end{array}$} & \multicolumn{3}{|c}{ Cases of hydrocephalus } \\
\cline { 3 - 5 } & & No. & $\%$ & Significance \\
\hline-39 & 10 & 2 & 20 & \\
$40-49$ & 36 & 7 & 19 & \\
$50-59$ & 31 & 9 & 29 & \\
$60-69$ & 52 & 23 & 44 & \\
$70-79$ & 38 & 23 & 61 & \\
$80-$ & 3 & 2 & 67 & \\
\hline$\leqq 64$ & 100 & 26 & 26 & \\
$\geqq 65$ & 70 & 40 & 57 & \\
\hline Total & 170 & 66 & 39 & \\
\hline
\end{tabular}

率をみると，年齢が高くなるにつれてその率も上昇してい た (Table 3). 我々の症例は 65 歳未満 100 例に対して 65 歳以上の高齢者が 70 例と多く，したがって，全体的に $\mathrm{H}$ 率が高かったのは，高年齢も関係しているものと考えられ た.

\section{2. 動脈瘤の部位}

水頭症は, AcomA 51 例中 26 例 $51 \%$, IC-PC 62 例中 26 例 $42 \%$, MCA 57 例中 14 例 $25 \%$ の順で発現し, midline に近い動脈瘤ほど $\mathrm{H}$ 率が高く, AcomA と $\mathrm{MCA}(p<$ $0.01)$ ，IC-PC と MCA $(p<0.05)$ では有意な差がみられた (Table 4).

\section{3. 術前重症度}

術前重症度別の H 率は, grade I ・ II 77 例中 18 例 $23 \%$, grade III 36 例中 16 例 $44 \%$, grade IV 30 例中 23 例 $77 \%$ で，いずれの grade 間においても有意な差がみられた $(p<0.01)$ (Table 4).

\section{CT 所見}

CT group と H 率は, group I では水頭症発現例はなく group II で 62 例中 19 例 31\%, group III 81 例中 42 例 $52 \%$, group IV 22 例中 5 例 $23 \%$ で, group IIIにH率が高 く, group III と group II , IVには有意な差がみられた $(p<$ 0.01) (Table 4).

\section{DIND}

DIND と H 率について検討した。いずれの部位におい ても DIND をきたした例の $\mathrm{H}$ 率が高く, 全体では DIND をきたさなかった症例 100 例中 21 例 $21 \%$ に対し, DIND をきたした症例 56 中 33 例 $59 \%$ と有意な差がみられた $(p<0.01)$ (Table 5).
Table 4 Incidence of hydrocephalus

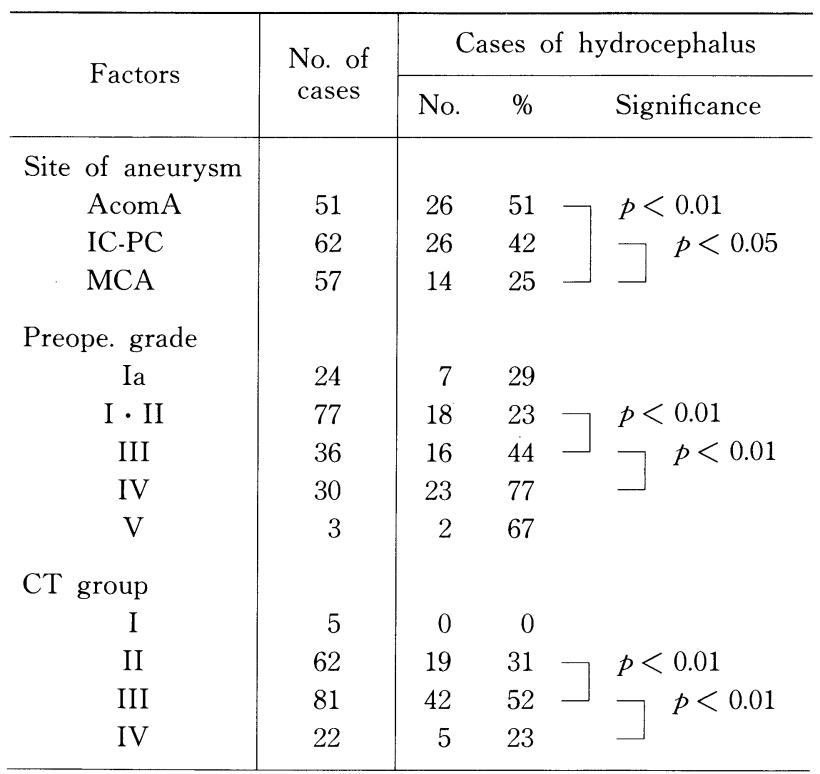

Table 5 Incidence of hydrocephalus

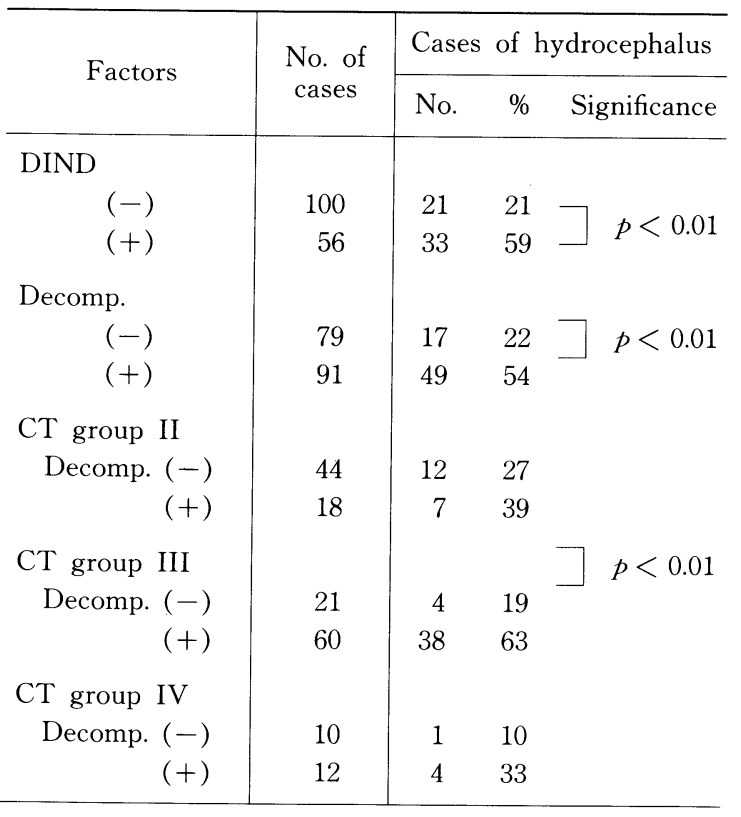

Decomp. indicates decompression.

\section{6. 広範囲減圧開頭術}

我々が行っている広範囲減圧開頭術のDINDに対する

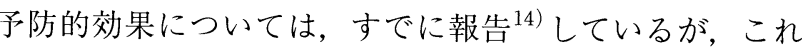
と水頭症の関係について検討した。いずれの部位において も外減圧例で $\mathrm{H}$ 率が高く, 全体でも非外減圧例 79 例中 17 例 $22 \%$ に対して外減圧例 91 例中 49 例 $54 \%$ で，有意な 差 $(p<0.01)$ がみられた (Table 5). さらに同じ CT group において外減圧の有無による $\mathrm{H}$ 率の違いがあるか否かを 検討したところ，CT group III において 外減圧例の H 率 
Table 6 Outcome and hydrocephalus

\begin{tabular}{|c|c|c|c|c|c|c|c|c|c|}
\hline & \multirow{2}{*}{$\begin{array}{l}\text { No. of } \\
\text { Cases }\end{array}$} & \multicolumn{5}{|c|}{ Outcome } & \multirow{2}{*}{$\begin{array}{c}\text { Good } \\
\text { outcome } \\
(\mathrm{G}+\mathrm{M})\end{array}$} & \multirow{2}{*}{$\%$} & \multirow{2}{*}{ Significance } \\
\hline & & G & $\mathrm{M}$ & S & $\mathrm{V}$ & $\mathrm{D}$ & & & \\
\hline Hydrocephalus & 66 & 13 & 9 & 30 & 12 & 2 & 22 & 33 & \multirow{2}{*}{$p<0.01$} \\
\hline No hydrocephalus & 104 & 66 & 15 & 18 & 4 & 1 & 81 & 78 & \\
\hline
\end{tabular}

Classification of the outcome is based on the grading system of the Glasgow Outcome Scale. G indicates good recovery; M, moderately disabled; S, severely disabled; V, vegitative survival; D, Dead. Good outcome means the sum of good recovery and moderately disabled.

が63\%であったのに対して非外減圧例では $19 \%$ と低く, 有意な差 $(p<0.01)$ がみられた (Table 5). CT group II と Nに扔いては外減圧例の $\mathrm{H}$ 率が高い傾向にあったが，有 意な差は認められなかった。

\section{Outcome}

Glasgow outcome scale における good recovery および moderately disabled good outcome と評価したところ, いずれの部位においても水頭症合併例で good outcome が 少なく，全体では水頭症非合併例で good outcome は 104 例中 81 例 $78 \%$, 水頭症合併例では 66 例中 22 例 $33 \%$ で り，有意な差 $(p<0.01)$ がみられた (Table 6).

\section{考察}

破裂脳動脈瘤に続発する水頭症の発現は, Fox ら ${ }^{4)}$ の review によると 1 ～63\%と報告者によりかなりの差がみ られている，これは，その診断方法の違いによることも考 えられるが，水頭症の発現に関与する因子が多彩であるこ とも大きく関与しているものと思われる. 水頭症の発現に 関与している因子として報告されているものは(1) 年齢2)6)

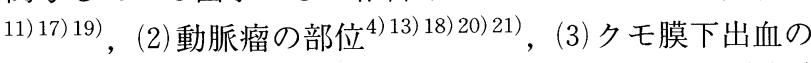
重症度 ${ }^{6)}$ 19) 23), (4) クモ膜下血腫量 ${ }^{9)}$ 19),$(5)$ 複数出血 ${ }^{5) 613)}$ ${ }^{23)}$ ，(6)抗線溶療法 ${ }^{2)}$ 16) 19)，(7)脳血管攣縮 ${ }^{2) 6) ，(8) ト ゙ レ ナ ー ~}$ ジ1) 18)21)22),(9) 造影 CT における gyral enhancement ${ }^{19)}$ どである.

年齢については, 若年者の方が水頭症になりやすいとい

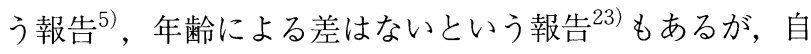
験例では 65 歳以上で $\mathrm{H}$ 率が高く, 水頭症例の平均年齢が 高い傾向にあるという多くの従来の報告 ${ }^{226111) 17) 19)}$ と同様 の結果であった. 最近では高齢者を 65 歳以上とするのは 異論があろうが, Table 3 にも示したように年齢が進むに つれて $\mathrm{H}$ 率が高くなっており, 年齢は水頭症の発現に関 与する一因子と考えられる。ではなぜ高齢者に水頭症が発 現しやすいか. 一つには潜在的な脳萎縮のため出血が広く クモ膜下腔に流れ込みやすく，これらの血腫が髄液循環を 32 脳卒中の外科 $22: 1994$
障害する可能性である。このことは高齢者に重症例が多い ことからも容易に推察できる。もう一つは, クモ膜絨毛以 外の髄液吸収経路として考えられている lesser pathway ${ }^{15)}$ (軟膜, クモ膜, 脈絡叢, 脳室壁, 脳血管外膜, 毛細血管 など)が年齢的変化を受け，すでに機能低下をきたしてい る可能性である. 特発生 NPHにおいても加龄による髄液 循環障害をその病因の一つとして考える向きもあり ${ }^{7)}{ }^{12)}$, このような背景にクモ膜下出血が起こった場合, それがた とえ軽度なものでも水頭症をきたしてくる可能性は十分あ ると思われる。

動脈瘤の部位については, 従来の報告 ${ }^{4)}$ 13) 18) 20) 21) と同 様に AcomA において H 率が高かった。また自験例では MCA に比べて IC-PCにH率が高く, midline に近い動脈 瘤では水頭症をきたしやすいと考えられた。これは出血が 濔漫性になりやすい部位の動脈瘤ほど水頭症をきたしやす いことを裏付けているものと思われる.

術前重症度についても従来の報告6) 19) 23) と同様に grade の高いものほどH 率が高かった. grade の高い例では一 般に出血もひどく, 頭蓋内圧立進, 脳浮腫などが髄液循環 を障害することは容易に推察できる。このような症例では 脳圧をコントロールするために脳室あるいは脳槽ドレナー ジが必須であり, しばしば行われる方法であるが, ドレ ナージが髄液の脳表への流れを阻止し, その結果クモ膜の 癒着をもたらし, 水頭症の発現を助長すると考えられる 18)21)22).しかし, 逆にKolluri ら ${ }^{13)}$ はドレナージにより血 性髄液を排除することが水頭症の発生を減少させたとして いる. Auer ら ${ }^{1)}$ は, 両者を考慮してドレナージの開放を 間欠的に行ったところ水頭症の発生が低く抑えられたとし その有効性を報告している. 我々は, ほとんどの症例で脳 室あるいは脳槽ドレナージを行っており, その有無による 水頭症発現の差は検討できなかったが，Auerらの方法は， 今後考慮されるべき方法と考えられる。

Fisher らの分類と水頭症の関係も他の報告9) 19) と同様 で, クモ膜下血腫量の多い group III で II , I より H率が有 意に高かった. Fisher 分類は, 本来症候性脳血管攣縮を 予知する目的で作られたものであるが，同時に水頭症の発 
現を予測する上でも意味のある分類と思われる，術中クモ 膜下血腫を可及的に除去する努力が DINDを予防し，さ らに水頭症の発現率を低下させるならば，これも試みられ るべき方法と考えられる.

vasospasm と水頭症の関係についても比較的古くから報 告がある ${ }^{5(6) 18) 20)}$. Galera ら ${ }^{5)}$ は, 水頭症例では $68 \%$ に血 管撮影上 spasm がみられたのに対し, 正常脳室例では spasm は $41 \%$ にかみられなかったと報告している。ま た, Black ら ${ }^{2)} も$ 水頭症をきたしたものでは $93 \% に$ vasospasm がみられ，一方そうでないものは $34 \%$ にasospasm がみられたにすぎなかったという結果から, クモ膜 下血腫はvasospasm と水頭症の共通因子であるとし両者 の関係を強調している. しかし, 茂野ら ${ }^{18)}$ は, NPH と vasospasmの高い相関は認めながらも vasospasm が原因 というよりは, 脳底槽あるいは Sylvian fissure の血塊が vasospasmをもたらし，かつNPH の原因になると考えて いる． 井澤ら ${ }^{9)}$ は， CT 上クモ膜下血腫が同程度である Fisher group IIIの患者においても両者の関係を認め, こ れにはクモ膜下腔髄液路 (major pathway) の障害に先行す る急性水頭症や脳血管攣縮により二次的に起こる脳実質内 髄液路 (minor pathway) の障害が関与していると報告して いる.

減圧開頭術と水頭症の関係については，いまだ報告がな い. 我々は, クモ膜下出血急性期には多くの症例で脳血流 量が減少していること, 頭蓋内圧方進は脳灌流圧を低下さ せ脳血管攣縮の時期には，これらがさらに血流障害をもた らし悪循環に陥るであろうと考え, 急性期広範囲減圧開頭

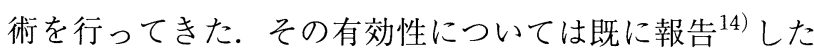
が，一方ではシャント手術を要する水頭症の発現を高めた 結果になった，減圧開頭下では，多くは脳が骨縁より膨隆 し，これが血液を含んだ髄液の循環を妨げ，後に生じる leptomeningeal fibrosis を助長するのかもしれない.

以上のように水頭症の発現因子を検討してみると, 水頭 症を起こしてくる背景には予後に影響するさまざまな要因 が含まれている，すなわち，高齢に伴うさまざまな問題で あり，また重症度が高ければ多くはクモ膜下血腫量も多く しかも脳血管攣縮をきたしやすくなってくる. 同じ水頭症 であっても, 単純な髄液循環障害により症状を呈してくる ものは, 我々の症例でもシャント手術により症状の改善が みられ, 予後良好であった。しかし, 種々の因子が重複し ていると思われた症例では髄液循環障害だけではなく，そ れまでに至る脳実質障害を合わせもっており，したがって 水頭症合併例の予後が非合併例に比べて不良であったのは 当然の結果ともいえる. これら水頭症の発現に関与する因 子を可能な限り排除することが，水頭症の発現頻度を低下 させ,ひいては予後の改善につながるものと考えられた。

\section{結語}

1. 破裂脳動脈瘤直達手術例 183 例のうち急性期死亡 13 例を除いた 170 例中 66 例 $39 \%$ に水頭症をきたしシャ ント手術を行った.

2. 水頭症は, 高齢者, midline に近い動脈瘤, 術前重症 度の高い例, クモ膜下血腫の多い例，外減圧術を加え た例に多く発生した。

3. 水頭症合併例は, 非合併例に比べて手術成績が不良で あった。

\section{文献}

1) Auer LM, Schneider GH, Auer T: Computerized tomography and prognosis in early aneurysm surgery. J Neurosurg 65: 217-222, 1986

2) Black PM: Hydrocephalus and vasospasm after subarachnoid hemorrhage from ruptured intracranial aneurysms. Neurosurgery 18: 12-16, 1986

3) Fisher CM, Kistler JP, Davis JM: Relation of cerebral vasospasm to subarachnoid hemorrhage visualized by computerized tomographic scanning. Neurosurgery $6: 1-9,1980$

4) Fox JL: Secondary complications of the subarachnoid hemorrhage. In: Intracranial Aneurysms, Springer-Verlag, New York/Berlin/Heidelberg/Tokyo, 1983, pp 184-217

5) Galera R, Greitz T: Hydrocephalus in the adult secondary to the rupture of intracranial arterial aneurysms. J Neurosurg 32: 634-641, 1970

6) 東健一郎, 波多野光紀, 岡村知實, ほか：〈も膜下出血後 の脳室拡大と髄液循環障害. 脳神経外科 7: 1145-1154, 1979

7）平井 収, 菊池晴彦, 石川正恒: 正常圧水頭症の病態生理 と治療. 脳神経外科速報 1: 17-30, 1991

8) Hunt WE, Kosnik EJ: Timing and perioperative care in intracranial aneurysm surgery. Clin Neurosurg 21: 79-89, 1974

9）井澤一郎，頃末和良，浜野聖二，ほか：脳動脈瘤によるく も膜下出血後の水頭症と脳血管攣縮. 脳神経外科 16: 487492, 1988

10) Kassell NF, Sasaki T, Colohan ART, et al: Cerebral vasospasm following aneurysmal subarachnoid hemorrhage. Stroke 16: 562-572, 1985

11）加藤庸子, 佐野公俊, 山口千賀志, ほか：高齢者破裂脳動 脈瘤の特徵および手術療法の検討. Geriatric Neurosurgery 2: $38-42,1990$

12) Kieffer SA: Normal pressure hydrocephalus. Geriatrics 29: $77-88,1974$

13) Kolluri VRS, Sengupta RP: Symptomatic hydrocephalus following aneurysmal subarachnoid hemorrhage. Surg Neurol 21: 402-404, 1984

14）宮田伊知郎, 津野和幸, 正岡哲也, ほか：クモ膜下出血後 の Delayed Ischemic Neurological Deficits に対する広範囲 減圧開頭術の予防的効果についての検討. Neurol Med Chir (Tokyo) 29: 735-739, 1989

15）岡部慎一：クモ膜下出血の䯣液吸収障害一クモ膜下腔線維 増殖との関係一. 脳神経外科 18: 439-445, 1990

16) Park BE: Spontaneous subarachnoid hemorrhage complicated by communicating hydrocephalus: Epsilon amino caproic acid as a possible predisposing factor. Surg Neurol 11: 
73-80, 1979

17）佐藤 章，中村 弘，小林繁樹，ほか：高齢者急性期破裂 脳動脈瘤に対する治療方針の検討. Geriatric Neurosurgery 1: 30-33, 1989

18）茂野卓，斎藤 勇，有竹康一，ほか：破裂脳動脈瘤急性 期手術後の水頭症一頭蓋内圧連続測定の意義一. Neurol Med Chir (Tokyo) 19: 592-535, 1979

19）椎野顯彦，鈴木文夫，中澤拓也，ほか：破裂脳動脈瘤と水 頭症. 脳神経外科 16: 493-497, 1988

20) Vassilouthis J, Richardson E: Ventricular dilatation and communicating hydrocephalus following spontaneous subarachnoid hemorrhage. J Neurosurg 51: 341-351, 1978
21) Yamamoto I, Hara M, Ogura K, et al: Early operation for ruptured intracranial aneurysms: Comparative study with computed tomography. Neurosurgery 12: 169-174, 1983

22) Yamamoto I, Shimoda M, Yamada S: Indications for cisternal drainage in conjunction with early surgery for ruptured aneurysms and timing of its discontinuation. Neurol Med Chir (Tokyo) 29: 407-413, 1989

23) Yasargil MG, Yonekawa Y, Zumstein B, et al: Hydrocephalus following spontaneous subarachnoid hemorrhage: Clinical features and treatment. J Neurosurg 39:, 474-479, 1973 